\title{
PWE-115 THE PRAGUE C \& M CRITERIA FOR GRADING BARRETT'S OESOPHAGUS: A LIVE ENDOSCOPY EVALUATION OF OBSERVER AGREEMENT
}

doi:10.1136/gut.2011.239301.378

J Shutt, ${ }^{1, *}$ D Chan, ${ }^{2}$ C Boger, ${ }^{3}$ P Patel ${ }^{2}$ Gastroenterology, Dorset County Hospital Foundation Trust, Dorchester, UK; ${ }^{2}$ Gastroenterology, Southampton University Hospital Trust, Southampton, UK; ${ }^{3}$ Gastroenterology, Royal Bournemouth Hospital, Bournemouth, UK

Introduction To validate the Prague $\mathrm{C}$ and $\mathrm{M}$ criteria for the endoscopic diagnosis and grading of Barrett's oesophagus (BO) in a real-time clinical setting between two experienced endoscopists in a University teaching hospital in the UK.

Methods Forty consecutive cases with BO were studied. A nurse endoscopist applied the Prague $\mathrm{C}$ and $\mathrm{M}$ criteria to record the Circumferential and Maximal extent of $\mathrm{BO}$ on push and pull endoscopy, this was repeated on pull endoscopy by a doctor (blinded to the initial assessment, with the nurse endoscopist not present). Landmark measurements were recorded by an independent observer. Intra- and inter-rater agreement regarding the length of $\mathrm{C}$ and $\mathrm{M}$ was evaluated by the correlation coefficient and Bland-Altman analysis.

Results The Pearson correlation coefficients ( $r$ ) for nurse pull against push endoscopy were 0.89 for $\mathrm{C}$ and 0.87 for $\mathrm{M}$ $(p<0.001)$, and for doctor against nurse were 0.76 for $C$ and 0.80 for $\mathrm{M}(\mathrm{p}<0.001)$. Comparing pull against push endoscopy, the exact rates of agreement were $15 / 40$ and $12 / 40$ for $C$ and $M$ respectively, differing by $1 \mathrm{~cm}$ in $30 / 40$ and $27 / 40$, and by $2 \mathrm{~cm}$ in 30/40 and 36/40 respectively. There were 5 and 4 cases with differences of 3 or $4 \mathrm{~cm}$ for $\mathrm{C}$ and $\mathrm{M}$ respectively. Comparing doctor against nurse, the exact rates of agreement were $8 / 40$ and $6 / 40$ for $C$ and $M$ respectively, differing by $1 \mathrm{~cm}$ in $20 / 40$ and $21 / 40$, and by $2 \mathrm{~cm}$ in $30 / 40$ and $29 / 40$ respectively. There were 9 and 11 cases with differences of 3 or $4 \mathrm{~cm}$ for $C$ and $M$ respectively, and 1 case where $C$ differed by $5 \mathrm{~cm}$. From the Bland-Altman analysis, the mean difference in $\mathrm{C}$ between pull and push endoscopy was $0.33 \mathrm{~cm}$ (95\% CI -0.22 to 2.00$)$, with limits of agreement from -2.59 to $3.24 \mathrm{~cm}$. For $\mathrm{M}$, the mean difference between pull and push endoscopy was $0.63 \mathrm{~cm}$ (95\% CI 0.07 to 2.03 ), with limits of agreement from -2.33 to $3.58 \mathrm{~cm}$. The mean difference in $\mathrm{C}$ between doctor and nurse was $-0.03 \mathrm{~cm}(95 \% \mathrm{CI}-0.82$ to 2.94$)$, with limits of agreement from -4.31 to $4.26 \mathrm{~cm}$. For $\mathrm{M}$ the mean difference between doctor and nurse was $-0.33 \mathrm{~cm}(95 \% \mathrm{CI}-1.09$ to 2.81$)$, with limits of agreement from -4.41 to $3.76 \mathrm{~cm}$.

Conclusion There was good agreement for interobserver C and $\mathrm{M}$ values of $\mathrm{BO}$ at live endoscopy, but with clinically significant limits of agreement that must be considered in any studies that use the Prague criteria, especially in trials that report a reduction in the length of $\mathrm{BO}$ as an end point. In this real-time clinical setting, patient movement and retching, compounded by the lack of $1 \mathrm{~cm}$ markings on the endoscope may well have contributed to this reduced degree of agreement.

Competing interests None.

Keywords Barrett's oesophagus, Endoscopic Classification, Prague $\mathrm{C}$ and $\mathrm{M}$. 